Publisher homepage: www.universepg.com, ISSN: 2663-6913 (Online) \& 2663-6905 (Print)

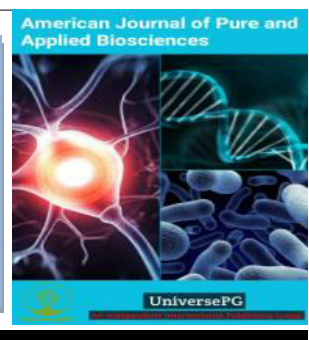

\title{
Molecular Identification and Characterization of Smartphone Screen Associated Pathogenic Bacteria
}

\author{
Shirmin Islam ${ }^{1}$, Md. Moniruzzaman ${ }^{1}$, Md. Joy Pramanik ${ }^{1}$, Tabassum Jabin ${ }^{1}$, Mst. Merina Mostari ${ }^{1}$, Jui \\ Biswas $^{1}$, Al-Imran ${ }^{1}$, Md. Salah Uddin ${ }^{1}$, Md. Abu Saleh ${ }^{1}$, Shahriar Zaman ${ }^{1}$ \\ ${ }^{1}$ Microbiology Laboratory, Department of Genetic Engineering and Biotechnology, University of Rajshahi, Rajshahi- \\ 6205, Bangladesh. \\ *Correspondence Email: $\underline{\text { saleh@ ru.ac.bd }}$
}

\begin{abstract}
Mobile phone is a device that keeps in contact with our sensitive body parts including faces, hands, nose, ears, and lips, etc. most of the time. Although we know many bad aspects of mobile phones; we are indifferent to its bacterial contamination. Smartphone screen is an endless reservoir of pathogenic bacteria and works as an object in spreading those bacteria. The purpose of the study was to identify pathogenic bacteria from smartphone screen and finding some common causes of bacterial contamination. So, a public survey was conducted among 100 students from the Dept. of Genetic Engineering \& Biotechnology, University of Rajshahi to know the uses pattern of their particular smartphone. Then, for the lab-based work samples were collected from the smartphone screen of the students by sterile swabs moistened with normal saline water. Among the samples, four strains were selected based on bacterial concentration for further analysis. Out of four, two strains were gram-positive and two were gram-negative. Biochemical tests indicated that all of them were pathogenic and the selected gram-positive bacteria were coagulase-positive Staphylococcus species and coagulase-negative Staphylococcus species.16S-rRNA gene sequencing identified the selected two gram negative strains as Stenotrophomonas maltophilia and Klebsiella pneumoniae. The antibiotic sensitivity test referred that all the bacteria were multidrug resistant and may be dangerous for compromised immune patients.
\end{abstract}

Keywords: Mobile phone screen, Pathogenic bacteria, Compromised immune patients, and Characterization.

\section{INTRODUCTION}

Mobile phone is a device that brings the whole world into our hands. Now it is impossible to think of a day without a mobile phone. In this twenty-first century about 3.5 billion people are using smartphones around the world (https://www.statista.com/ statistics/330695/number-of-smartphone-users world wide/). We use mobile phones for commercial, educational and personal purposes. The addiction of mobile phones is becoming the newest cigarette for the young stars (Vivekananda et al., 2017). Mobile phone screens are a potential source of nosocomial pathogenic bacteria (Bodena et al., 2019). A typical mobile phone is carrying over 25,000 bacteria per square inch which is much higher than toilet seats (https://info.debgroup.com/ blog/bid/290652/yourmobile-phone-is-dirtier-than-you-think). Continuous use of touch screen produces heat which provides favorable condition for bacteria to grow and multiply (Chauhan et al., 2018). Mobile keeps in touch with the close proximity of our face, nose, ears, hands (Morubagal et al., 2017).

We use mobile phones in hospitals, markets, in public gatherings, while eating as well as washrooms, which are a common source of 
contamination. The pathogens can be transmitted easily through sharing personal phones with others and those pathogens can be dangerous for compromised immune patients and cause mild to moderate diseases (Koscova et al., 2018). We touch our phone screen more than other items on a single day and are not aware of cleaning the phone screen. 9 out of 10 cell phones contain germs that can cause flu and other diseases (http://sanimag.sanimarc.com/ shocking-statistics-on-cell-phones-andgerms). Common bacteria found in phone screen were multidrug resistant Staphylococcus, coagulase negative Staphylococcus, E. coli, K. pneumoniae, Staphylococcus aureus, Acinetobacter species, Pseudomonas spp. and Enterococcus spp. etc (Pal et al., 2015). Generally those pathogens do not attack a healthy person but could pose catastrophic effects to a cancer patient or premature infant or any other immune compromised person as it settles into an incision (Koscova et al., 2018).

The present research work deals with the isolation, characterization, antibiotic sensitivity testing and molecular identification of the bacteria isolated from the smartphone screen of the students of the Department of Genetic Engineering and Biotechnology, University of Rajshahi and investigating the relationship between the bacterial contaminants present and the behavioral patterns of their smartphone as well as increasing awareness among people to maintain proper hygiene and healthy use of smartphone.

\section{MATERIALS AND METHODS}

This study was carried out over five months from June to Nov 2019. Total work was divided into two parts like public survey and lab-based work. The survey was administered among 100 students of the department of Genetic Engineering and Biotechnology, University of Rajshahi to know the uses pattern of their smartphone.

Public survey - The data were collected using a structured questionnaire, which was presented to the participants to complete. A consent form was also signed to let them know how their information would be used. All possible precautions were taken to maintain the reliability of the responses. The entire process of data collection was completed during May, 2019 to June 2019.
Sample collection - The samples of this study were collected from 10 mobile phones owned by 5 male and 5 female students of the Department of Genetic Engineering and Biotechnology University of Rajshahi. Twenty sterile swabs were used to take samples from the touch screen of 10 smartphone screens to determine bacterial contamination. Sterile cotton swab moistened with sterile saline was rolled over the phone screen and immediately inoculated to LB liquid media and incubated overnight at $37^{\circ} \mathrm{C}$. Growth was observed for 10 collected samples.

\section{Isolation and identification of bacteria from touch} screen of smartphone - Serial dilutions from the nutrient broth medium were poured-plated on count agar (PCA) and incubated for $24 \mathrm{~h}$ at $37^{\circ} \mathrm{C}$. Colony forming unit (CFU) assay was performed to detect the viable bacteria. Selected colonies were streaked on sheep blood agar plates (for heterotrophic bacteria), MacConkey agar plates (for coliform bacteria) and Mannitol salt agar (selective media for coagulase negative and positive staphylococcus) for $24 \mathrm{~h}$ at $37^{\circ} \mathrm{C}$ for colony isolation and morphological identification.

\section{Morphological and Biochemical identification}

Gram staining - Gram staining method was used to distinguish and classify gram negative and grampositive bacteria. In this process bacteria was stained with certain basic dyes and treated with iodine, the gram-positive bacteria retained the color of iodine and showed purple color while gram-negative bacteria showed pink color under microscope

Catalase test - Appropriate $\mathrm{H}_{2} \mathrm{O}_{2}$ was added to 24 hours tryptic soy agar slant culture. Organisms were identified with the capability of producing the enzyme that breaks down the hydrogen peroxide.

Methyl red test (MR Test) - Usually, Methyl Red Test is done to evaluate whether the microbe performs mixed acids fermentation or not. After inoculation of bacteria into the MR broth medium in test tubes, cultures were incubated at $37^{\circ} \mathrm{C}$ for $16-18$ hours for observation. Then, 2-3 drops of methyl red reagent were added and observed the yellow or red color of the media.

Simmons citrate agar test - Isolates were tested to determine the utilization of citrate as the prime source of carbon for metabolism. Results were 
recorded for change in color of citrate media. Citrate-positive result was interpreted by intense Prussian blue and in case of citrate-negative no color change occurs.

Urea hydrolysis test - Urease broth is a differential medium that tests the ability of an organism to produce an exo-enzyme, called urease, which hydrolyzes urea to ammonia and carbon dioxide. Color change of the medium was observed after incubation of the isolated bacteria at $35-37^{\circ} \mathrm{C}$ for 18 hours.

Triple sugar iron (TSI) test - Gram-negative enteric bacilli are identified through the dextrose, lactose and sucrose fermentation and hydrogen sulphide production on TSI test. Organisms that ferment dextrose monohydrate produce a variety of acids and change the color of the medium from red to yellow. The appearance of an alkaline (red) slant and an acid (yellow) butt after incubation indicates that the organism is a dextrose fermenter but is unable to ferment lactose and/or sucrose. Gas production $\left(\mathrm{CO}_{2}\right)$ is identified by the presence of cracks or bubbles in the medium.

Starch hydrolysis test - In starch hydrolysis test, starch-containing medium is used. Iodine reagent is added after inoculation and incubation (16 h) of the medium to detect the presence of starch. Iodine reagent reacts with starch to form a blue-black color in the culture medium. Clear halos surrounding colonies is indicative of their ability to digest the starch in the medium.

Eosin methylene blue (EMB) agar test - Eosin methylene blue agar is a selective media for the identification of gram-negative bacteria. It is a mixture of two stains, eosin and methylene blue in the ratio of 6:1. EMB medium slightly inhibits the growth of gram positive bacteria and provides a color indicator distinguishing between organisms that ferment lactose (e.g., E. coli) and those that do not (e.g., Salmonella, Shigella.)

Bismuth sulfite agar (BSA) test - Bismuth sulfite agar is a selective medium for the isolation and preliminary identification of Salmonella typhi and other salmonellae from sewage, water supplies, food and other products suspected of containing these pathogens. Bismuth and BLBG stop the growth of the gram-positive bacteria. Sulphur compounds provide a substrate for hydrogen sulphide production and the metallic salts in the medium stain the colony and surrounding medium black or brown in the presence of hydrogen sulphide.

Antibiotic sensitivity test - Antibiotic sensitivity and resistance pattern of the isolated pathogenic bacteria were tested according to the Kirby- Bauer disc diffusion method (Bauer et al., 1966). The isolated bacterial strains were grown overnight in nutrient broths at $37^{\circ} \mathrm{C}$ temperature and $160 \mathrm{rpm}$ for the antibiotic sensitivity test (Rahman et al., 2019). Then, LB agar medium was prepared for making culture plates. Approx-imately, (15-20) $\mathrm{ml}$ of the medium was poured in each petri dish and left in the laminar airflow cabinet for solidification. Then, overnight grown LB culture $(\mathrm{OD}=0.5)$ for both isolates was poured into nutrient plates and dried. Different antibiotic discs were used in this experiment (Table 1).

Table 1: List of antibiotic discs containing different concentration that was used in the antibiotic sensitivity test.

\begin{tabular}{|l|c|c|}
\hline Antibiotics & Symbol & Concentration \\
\hline Penicillin & P & 10 units/disk \\
\hline Amoxicillin & AXM & $10 \mathrm{mcg} /$ disk \\
\hline Gentamycin & GEN & $10 \mathrm{mcg} /$ disk \\
\hline Tetracycline & TE & $30 \mathrm{mcg} /$ disk \\
\hline Ciprofloxacin & CIP & $5 \mathrm{mcg} /$ disk \\
\hline Cefuroxime & CXM & $30 \mathrm{mcg} /$ disk \\
\hline Cefixime & CFM & $5 \mathrm{mcg} /$ disk \\
\hline
\end{tabular}

\section{Molecular analysis}

Genomic DNA of bacterial strains was isolated by using Maxwell Blood DNA Kit, Model: AS1010, Origin: Promega, USA. Gene fragments specific for the highly variable region of the bacterial $16 \mathrm{~S}$ rRNA gene was amplified by PCR using universal PCR primer (27 F - AGA GTT TGA TCM TGG CTC AG \& $1492 \mathrm{R}$ - GGT TAC CTT GTT ACG ACT T). The PCR products were subjected to $1 \%$ agarose gel electrophoresis and visualized on a UV Transilluminator for the presence of about $1500 \mathrm{bp}$ PCR products.

Amplified 16S rRNA gene PCR products were purified using Tiangen PCR purification kit (Beijing, China) and purified cycle sequenced products were 
analyzed with an ABIPrism 310 genetic analyzer. The 16S rRNA gene sequence was submitted to the GeneBank database using the BLASTN (http://www.ncbi.nih.gov/ BLAST/) algorithm.

\section{RESULTS}

Public survey - According to the survey, 95\% students used smartphones and only $5 \%$ used feature phones (Fig 1A). $75 \%$ of students knew that smartphone screens might contain bacteria (Fig 1B) but they were not aware of it. $92 \%$ of students took their phone to the bedside while sleeping (Fig 1C). Most of the students (84\%) did not use headphones or others while talking. So, the phone remains in close contact with their faces most of the time (Fig 1D).
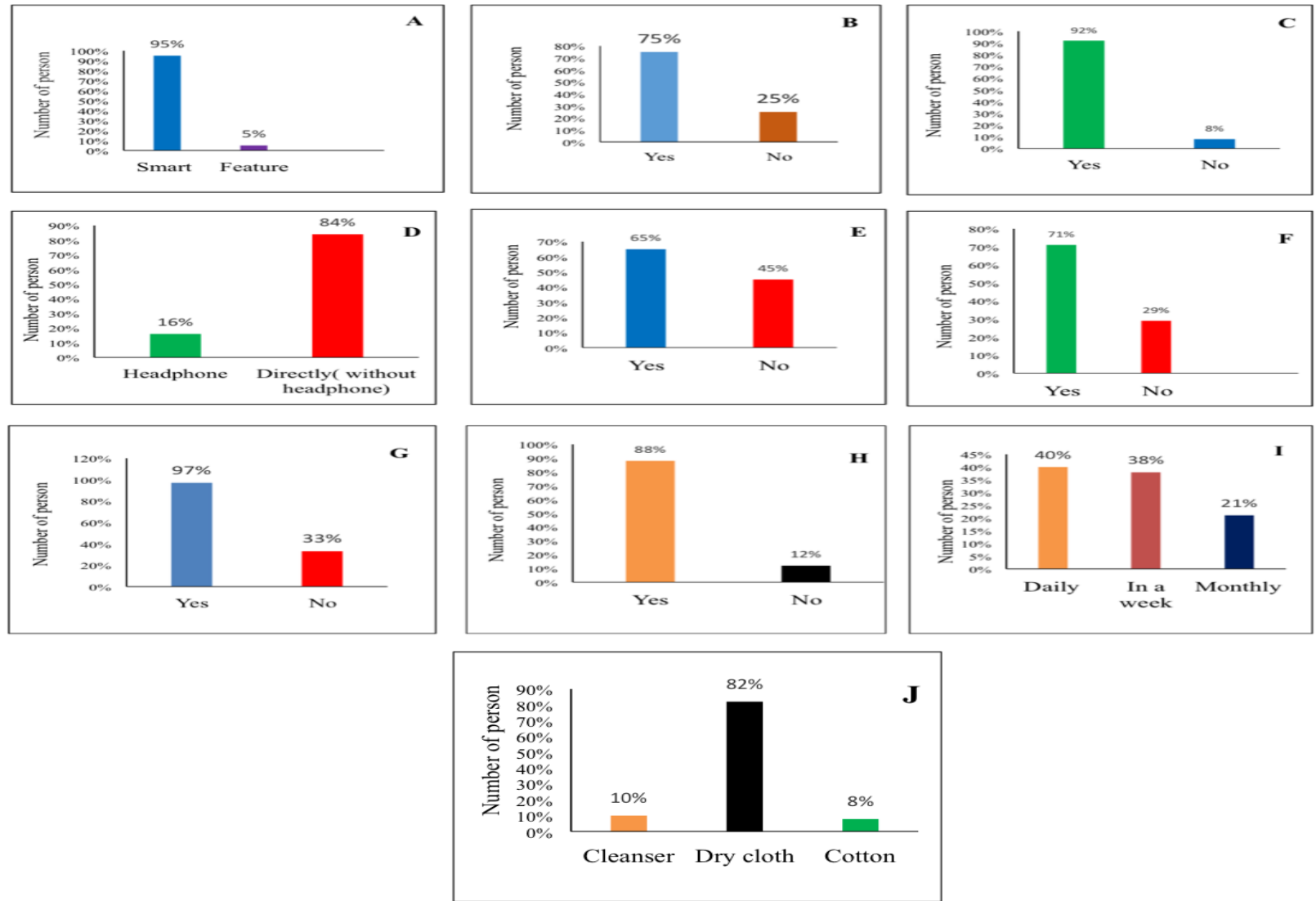

Fig 1: Diverse uses of mobile phones. (A), Types of phone used; (B), Having knowledge of bacterial contamination; (C), Keeping phone while sleeping; (D), Use of headphones; (E), Presence of scratch on phone screen; (F). Sharing phones with others; (G), Using phone at hospital; (H), Uses of the phone when they are sick;

(I), Cleaning pattern of phone; (J), Types of cleanser used.

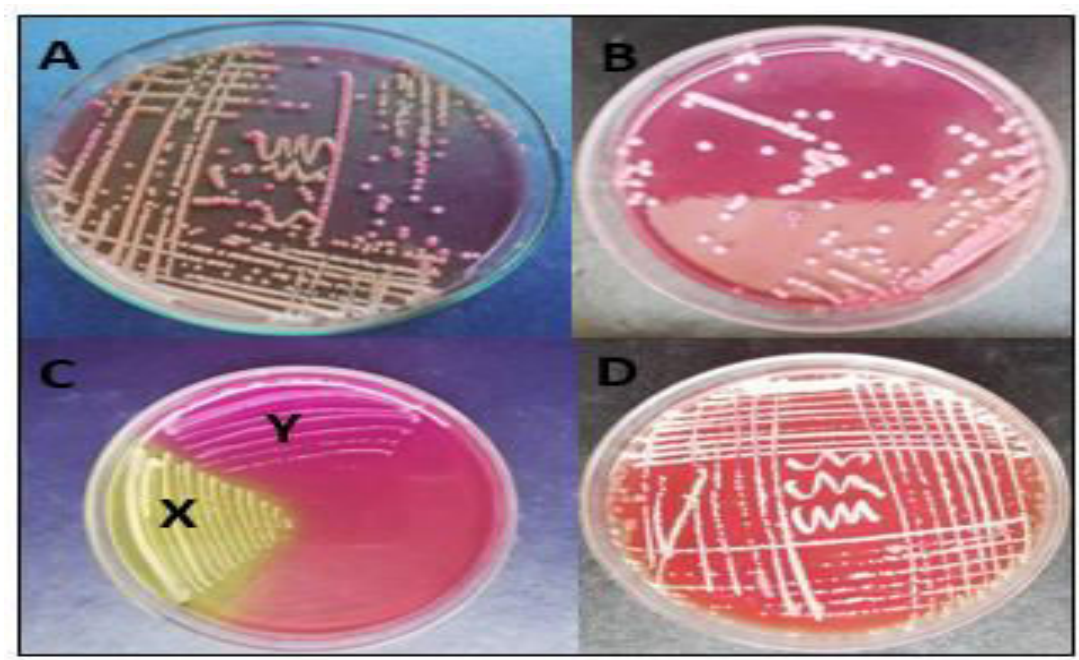

Fig 2: Streaking of isolated bacteria on various selective media. Isolate 1 on MacConkey Agar; (A), isolate 2 on MacConkey Agar; (B), Isolate 3 and isolate 4 on Mannitol Salt Agar, where X indicating coagulase positive and Y indicating coagulase negative; (C), beta hemolytic activity of isolate 3 on Blood Agar; (D). 
Table 2: Isolation of bacteria on selective media.

\begin{tabular}{|c|c|c|c|c|}
\hline Isolates Id & $\begin{array}{c}\text { MacConkey } \\
\text { Agar }\end{array}$ & $\begin{array}{c}\text { Mannitol Salt Agar } \\
\text { (MSA) }\end{array}$ & Blood Agar & Suspected organism \\
\hline Isolate 1 & Colorless colonies & No growth & $\begin{array}{l}\text { Gamma } \\
\text { hemolytic }\end{array}$ & Coliform bacteria \\
\hline Isolate 2 & $\begin{array}{l}\text { Pink colored } \\
\text { colonies }\end{array}$ & No growth & $\begin{array}{l}\text { Gamma } \\
\text { hemolytic }\end{array}$ & Coliform bacteria \\
\hline Isolate 3 & No growth & $\begin{array}{l}\text { Small yellow colored } \\
\text { colonies }\end{array}$ & $\begin{array}{c}\text { Beta } \\
\text { hemolytic }\end{array}$ & $\begin{array}{l}\text { Coagulase positive } \\
\text { Staphylococcus spp. }\end{array}$ \\
\hline Isolate 4 & No growth & $\begin{array}{l}\text { Small pink colored } \\
\text { colonies }\end{array}$ & $\begin{array}{r}\text { Gamma } \\
\text { hemolytic }\end{array}$ & $\begin{array}{l}\text { Coagulase negative } \\
\text { Staphylococcus spp. }\end{array}$ \\
\hline
\end{tabular}

65\% student's phone screen had scratch, which provides potential growth space for bacteria to multiply (Fig 1E). Sharing phones with others were also observed in $71 \%$ students (Fig 1F). Hospital, which is a reservoir of pathogenic bacteria, in such a place $97 \%$ students carried their phone without any protection (Fig 1G). 88\% of students used phones in compromised immune conditions (Fig 1H). Most of the students were careless about cleaning their phones, only $40 \%$ students cleaned their smartphone screen regularly (Fig 1I) and 10\% used cleanser to clean it (Fig 1J).

\section{Isolation of bacterial strains on selective media -}

Three selective media i.e. MacConkey agar medium, Mannitol salt agar medium and Blood agar medium were used for the isolation of bacteria. Isolate 1 and isolate 2 showed positive results on MacConkey agar medium. Isolate 1 produced colorless colony and isolate 2 produced pink colored colonies on MacConkey agar. Isolate 3 and isolate 4 were MacConkey negative (Fig $\mathbf{2}$ and Table 2).

On mannitol salt agar media, isolate 3 produced yellow colored colonies indicating coagulase positive Staphylococcus spp. and isolate 4 produced pink colored colonies indicating coagulase negative Staphylococcus spp. While isolate 1 and isolate 2 were MSA negative (Table 2). On blood agar media, only isolate 3 had beta hemolytic activity and others had gamma hemolytic activity (Table 2 ).

Morphological and biochemical tests - In gram's staining test isolate 1 and isolate 2 showed rod shaped pink colored colonies under microscope indicating gram negative bacteria whereas isolate 3 and isolate 4 were cocci shaped purple colored colonies indicating gram positive (Table 3 ).

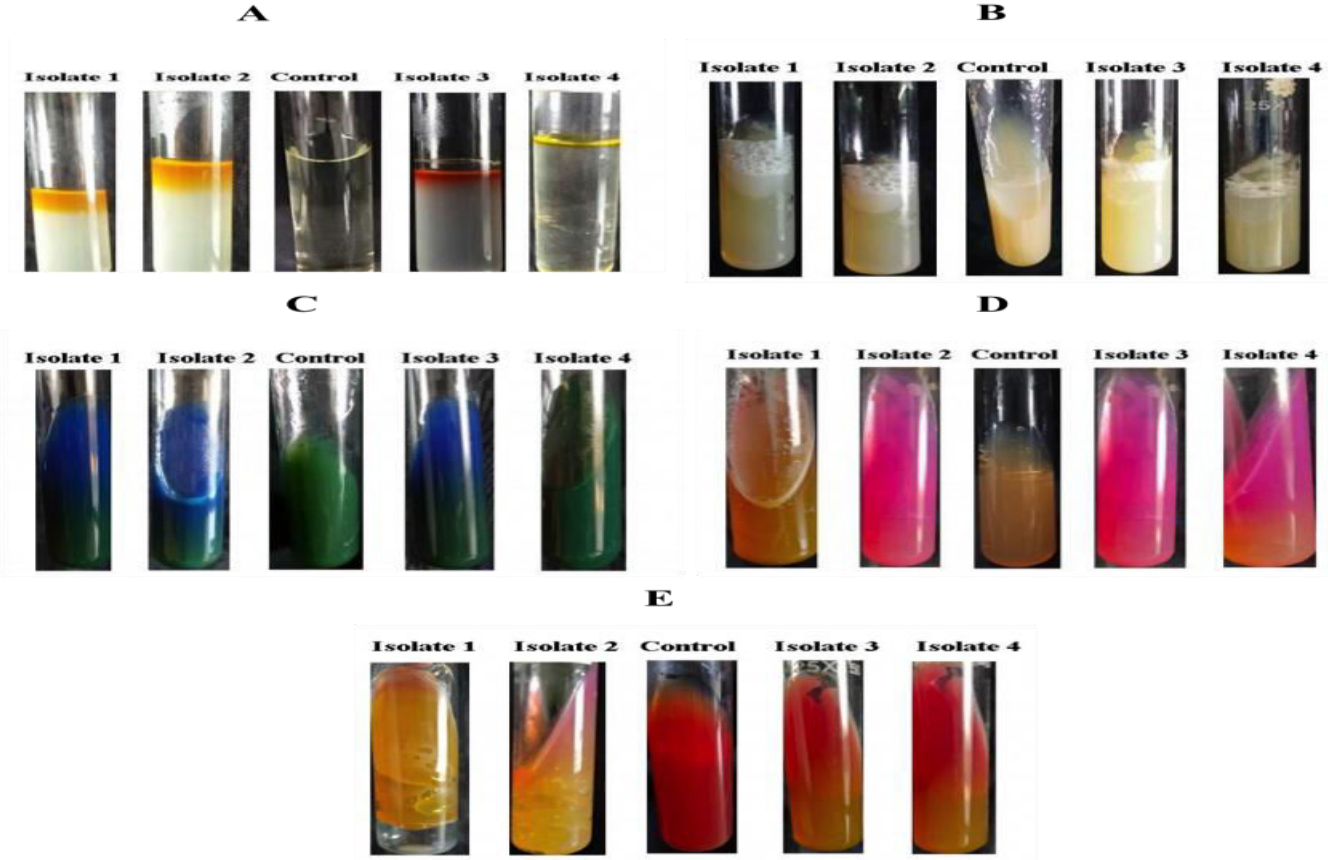

Fig 3: Biochemical test results of the four isolated strains. Methyl red test (A), Catalase test (B), Simmons citrate test $(\mathbf{C})$, Urea hydrolysis test $(\mathbf{D})$ and TSI test $(\mathbf{E})$. 
A
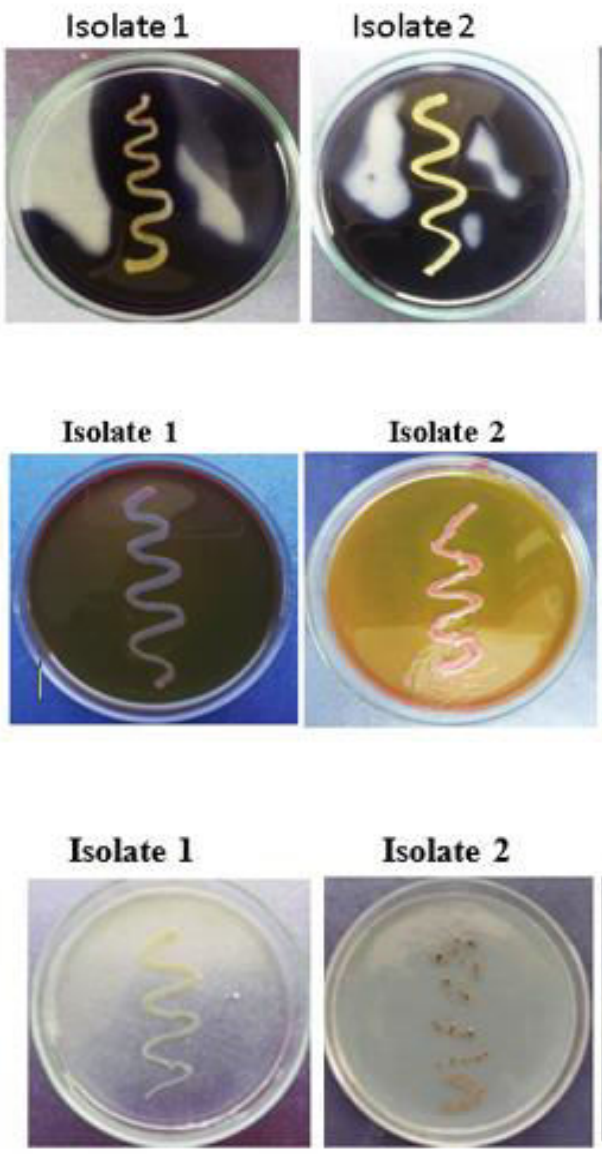

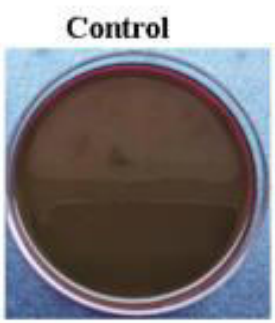

C

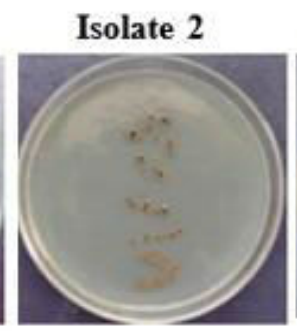

Control

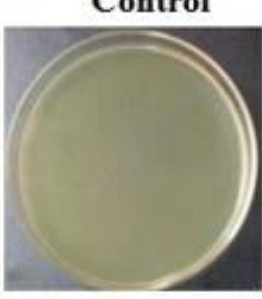

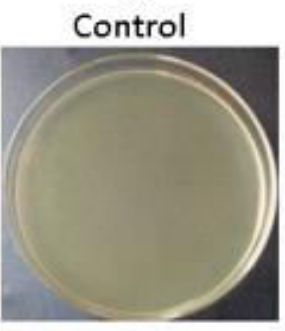

B
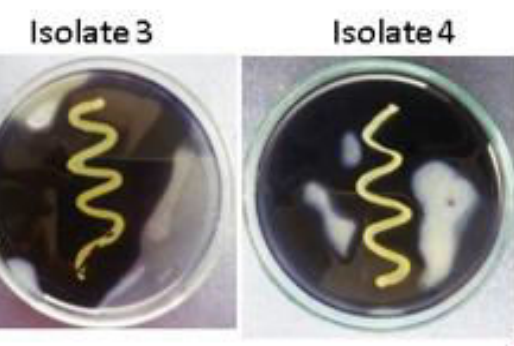

Isolate 3
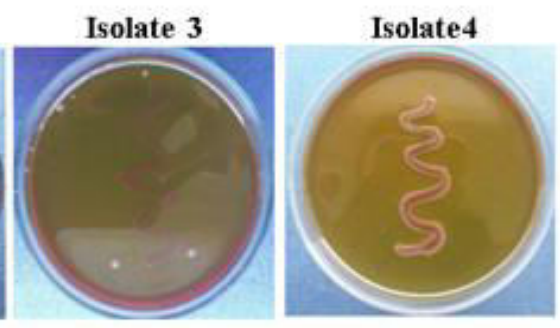

Isolate 3

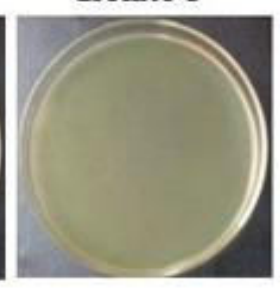

Isolate 4

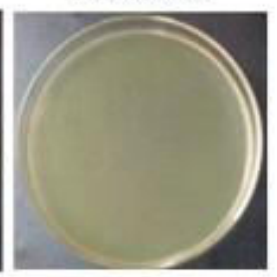

Fig 4: Biochemical test results of the four isolated strains. Starch agar test; (A), Eosin ethyl blue test; (B) and Bismuth sulfide agar test $(\mathbf{C})$.

Table 3: Biochemical tests results of four isolated strains.

\begin{tabular}{|l|c|c|c|c|}
\hline \multirow{2}{*}{ Tests name } & \multicolumn{3}{c|}{ Results } \\
\cline { 2 - 5 } & Isolate 1 & Isolate 2 & Isolate 3 & Isolate 4 \\
\hline Gram staining test & Gram negative & Gram negative & Gram positive & Gram negative \\
\hline Methyl Red test & Negative & Negative & Positive & Negative \\
\hline Catalase test & Positive & Positive & Positive & Positive \\
\hline Starch Agar test & Positive & Positive & Positive & Positive \\
\hline TSI test & Positive & Positive & Negative & Negative \\
\hline Simmon Citrate Agar test & Positive & Positive & Positive & Negative \\
\hline Urea test & Negative & Positive & Positive & Positive \\
\hline Bismuth sulfite agar (BSA) test & Positive & Positive & Negative & Negative \\
\hline (EMB) agar test & Positive & Positive & Positive & Positive \\
\hline
\end{tabular}

Biochemical test results are summarized in Table 3. Except isolate 3, other three isolates were methyl red negative (Fig 3A). All the isolates were positive in catalase, starch agar test and EMB agar test (Fig 3B, Fig 4A, Fig 4B, and Table 3). Isolate 1 and isolate 2 were positive against Simmons citrate, TSI and BSA test (Fig 3C, Fig 3E, Fig 4C, and Table 3). In urea hydrolysis test, except isolate 1 , all were positive (Fig 3D, and Table 3). 
Antibiotic sensitivity test - The results are presented in Table 4. From this table it was seen that all of the four strains were resistant to Amoxicillin, Cefixime and Penicillin. On the contrary all the strains were susceptible to Gentamicin \&
Ciprofloxacin. Cefuroxime is resistant for isolate 1 and isolate 2 but susceptible for isolate 3 and isolate 4. Tetracycline is resistant for isolate 1 , isolate 2 and isolate 3 but susceptible for isolate 4 (Table 4).

Table 4: Antibiotic sensitivity test results of the isolated strains.

\begin{tabular}{|c|c|c|c|c|c|c|c|c|}
\hline & \multicolumn{4}{|c|}{ Zone of inhibition (mm) } & \multicolumn{4}{|c|}{ Resistant pattern } \\
\hline & Isolate 1 & Isolate 2 & Isolate 3 & Isolate 4 & Isolate 1 & Isolate 2 & Isolate 3 & Isolate 4 \\
\hline $\begin{array}{l}\text { Gentamycin } \\
(\mathrm{CN})\end{array}$ & $14 \mathrm{~mm}$ & $18 \mathrm{~mm}$ & $18 \mathrm{~mm}$ & $13 \mathrm{~mm}$ & Susceptible & Susceptible & Susceptible & Susceptible \\
\hline $\begin{array}{l}\text { Cefuroxime } \\
\text { (CXM) }\end{array}$ & $6 \mathrm{~mm}$ & $6 \mathrm{~mm}$ & $19 \mathrm{~mm}$ & $16 \mathrm{~mm}$ & Resistant & Resistant & Susceptible & Susceptible \\
\hline Penicillin $(\mathrm{P})$ & $6 \mathrm{~mm}$ & $6 \mathrm{~mm}$ & $6 \mathrm{~mm}$ & $6 \mathrm{~mm}$ & Resistant & Resistant & Resistant & Resistant \\
\hline $\begin{array}{l}\text { Tetracycline } \\
\text { (TE) }\end{array}$ & $08 \mathrm{~mm}$ & $12 \mathrm{~mm}$ & $10 \mathrm{~mm}$ & $18 \mathrm{~mm}$ & Resistant & Resistant & Resistant & Susceptible \\
\hline Cefixin (CFM) & $08 \mathrm{~mm}$ & $6 \mathrm{~mm}$ & $6 \mathrm{~mm}$ & $6 \mathrm{~mm}$ & Resistant & Resistant & Resistant & Resistant \\
\hline $\begin{array}{l}\text { Amoxycillin } \\
\text { (AML) }\end{array}$ & $6 \mathrm{~mm}$ & $6 \mathrm{~mm}$ & $8 \mathrm{~mm}$ & $9 \mathrm{~mm}$ & Resistant & Resistant & Resistant & Resistant \\
\hline $\begin{array}{l}\text { Ciprofloxacin } \\
\text { (CIP) }\end{array}$ & $22 \mathrm{~mm}$ & $27 \mathrm{~mm}$ & $23 \mathrm{~mm}$ & $20 \mathrm{~mm}$ & Susceptible & Susceptible & Susceptible & Susceptible \\
\hline
\end{tabular}

Note: Resistant $\leq 10 \mathrm{~mm}$; Intermediate $=10-15 \mathrm{~mm} ;$ Susceptible $\geq 15 \mathrm{~mm}$

\section{Molecular identification}

The sequences (Fig 5) were blasted through NCBI blast tools. Isolated 1 (96.90\% similarity) and isolate 2 (97.24\% similarity) were identified as $S$. maltophilia (NC_010943.10.003) and $K$. pneumoniae (NC_015663.10.00081) respectively. Then for understanding the phylogenetic relationship among the bacteria isolated from mobile and related genera, a tree was constructed using neighbor joining algorithm with Clustal Omega software (Fig 6)

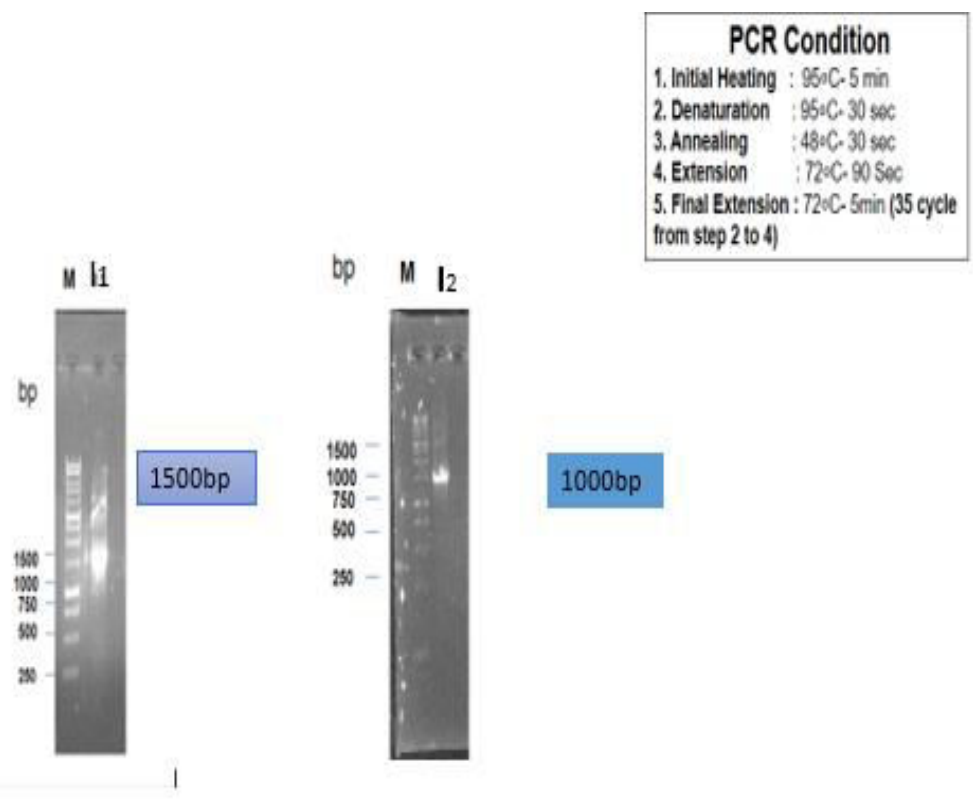

Fig 5:16s PCR rRNA profiles generated by 27F and 1492R primer from bacterial genomic DNA. 


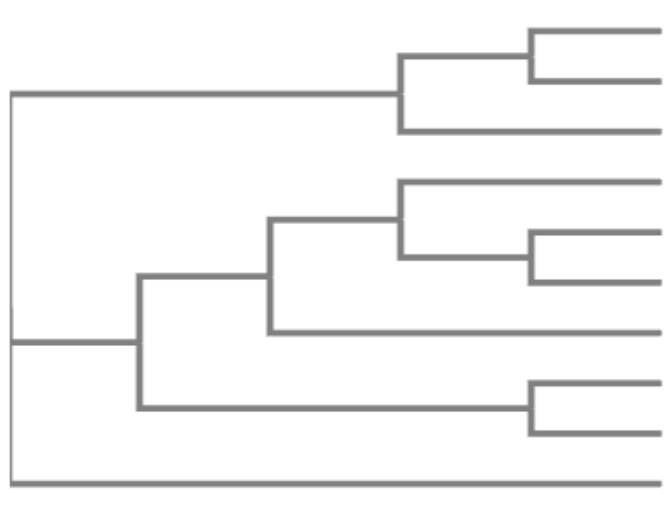

NC_010943.10.003

NZ_CP016294.10.00476

KC871534.1 0.00346

MN179354.1 0.02429

MK386776.1 0.00061

NC_015663.1 0.00081

JQ680798.1 -0.00246

MF511713.1 0.0035

KP728240.1 0.00271

MN173470.1 0.0005

Fig 6: Phylogenetic relationship of the mobile bacterial strains and related genera based on full size16S rRNA or 16SrDNA sequences. The tree was constructed using a neighbor-joining algorithm with Clustal Omega software.

\section{DISCUSSION}

Smartphones are an integral part of our life, truly becoming our own personal assistant. Phone screen is the endless reservoir of bacteria which poses health risks that are not present in any of the items we use in our daily lives and work as a means of disease transmission (Shahaby et al., 2012).

Students use mobile phones for their educational purposes as well as for their requirements. The research work was aimed to make people aware that their most useful smartphone can be a source of disease causing bacteria. So, personal hygiene and decontaminating smartphone screens are mandatory. Similar kind of work focusing on this purpose has not been attempted in Bangladesh before. In our work, a statistical survey was conducted among 100 students of the department of Genetic Engineering and Biotechnology, University of Rajshahi. Although $95 \%$ of students use smartphones, they do not use it smartly. Being the students of biological science, $75 \%$ students know that it may be a source of bacteria but their using pattern is not reflecting it. They used smartphones in the hospitals, in the public gatherings as well as in the washroom also, which is the source of bacteria. Those bacteria can attack us when our immunity becomes weak, in such an immune compromised condition $88 \%$ students use smartphones. Only $40 \%$ students clean their phones regularly, among them only $10 \%$ use cleansers.

Most of the persons used their phone without any protection thus causing more exposure to electromagnetic radiation and subsequently, increases the incidence of health complications. Different experimental data suggest that the various harmful components including electromagnetic radiation from cell phones can create life threatening diseases like cancer (Needhidasan et al., 2014).

So, making people aware of its healthy use is mandatory. On contrary for lab based work 10 samples were collected from the students smartphone screen, $100 \%$ of the samples were contaminated. Among the samples 4 strains were isolated. Morphological, biochemical and molecular analysis confirmed those isolates as S. matophilia, $K$. pneumoniae (According to 16S rRNA sequencing) and coagulase positive Staphylococcus spp. And coagulase negative Staphylococcus spp. (According to Bergeys Mannual of Determinative Bacteriology). K. pneumoniae, Staphylococcus spp. are common phone bacteria which were found by many researchers (Cerda et al., 2006; Al-Abdalall et al., 2010).

But this is the first report of S.matophilia in smartphones. All of the bacteria are multi drug resistant and biofilm producing nosocomial bacteria. S. matophilia is an emerging global opportunistic pathogen, causing hospital-acquired infections, such as bacteremia, pneumonia, endocarditis, and meningitis, as well as urinary tract, ocular, bone and joint, skin, soft tissue, and gastrointestinal infections (Alqahtani et al., 2017). K. pneumoniae is also a common phone screen bacteria, which causes severe infections, and may serve as a vehicle for the spread of nosocomial pathogens (Karabay et al., 2007). Coagulase positive and negative Staphylococcus are major human pathogen that causes a wide range of clinical infections such as bacteremia, infective 
endocarditis as well as osteo articular, skin and soft tissue infections, pleura pulmonary, and devicerelated infections and nosocomial infections ( $\mathrm{Yu}$ et al., 2017).

\section{CONCLUSION}

The present work clearly indicated that smart phones could be contaminated with gram-positive and gramnegative bacteria. Factors like irregular cleaning, presence of scratches, ages of phone and sharing mobile phones with others trends to alter the occurrence of different species of bacteria on the touch pad. Thus awareness should be made for the potential threats of mobile phones in harboring pathogens in order to reduce the risk of communityacquired infections.

\section{ACKNOWLEDGEMENTS}

We express our deepest gratitude and thanks to Almighty Allah and all those who have helped and supported us along the way. The authors received no funding from an external source.

\section{CONFLICTS OF INTEREST}

The author (s) declared no potential conflicts of the interest with respect to the research, authorship and/or publication of this article.

\section{REFERENCES}

1. Al-Abdalall AHA. (2010). 'Isolation and identification of microbes associated with mobile phones in Dammam in eastern Saudi Arabia', Journal of Family and Community Medicine, 17(1), 11-14. https://doi.org/10.4103/1319-1683.68783

2. Alqahtani JM. (2017). 'Emergence of Stenotrophomonas maltophilia nosocomial isolates in a Saudi children's hospital: risk factors and clinical characteristics', Saudi medical journal, 38(5), 521-527. https://doi.org/10.15537/smj.2017.5.16375

3. Bauer AW. (1966). 'Antibiotic susceptibility testing by a standardized single disc method', Am J clinpathol, 45, 149-158. PMID: 5325707

4. Bodena D, Teklemariam, Z, Balakrishnan, S \& Tesfa, T. (2019). 'Bacterial contamination of mobile phones of health professionals in Eastern Ethiopia: antimic- robial susceptibility and associated factors', Tropical medicine and health, 47, pp. 15. https://doi.org/10.1186/s41182-019-0144-y

5. Chauhan A, Garg, S, \& Ranjan, AA. (2018). 'Prevalence of microbial contamin-ation of mobile cell phones in general population of Delhi, India', J Exp Clin Microbiol, 1(1), 12-15.

6. Karabay O, Koçoglu, E \& Tahtaci, M. (2007). 'The role of mobile phones in the spread of bacteria associated with nosocomial infections, J Infect Dev Ctries, 1(1), 72-73.

7. Koscova J, Hurnikova, Z \& Pistl, J. (2018). Degree of bacterial contamination of mobile phone and computer keyboard surfaces and efficacy of disinfection with chlorhexidine digluconate and triclosan to its reduction, International $j$. of environmental research and public health, 15(10), pp. 2238.

https://doi.org/10.3390/ijerph15102238

8. Morubagal RR, Shivappa, SG, Mahale, RP \& Neelambike, SM. (2017). 'Study of bacterial flora associated with mobile phones of healthcare workers and nonhealthcare workers', Iranian journal of microbiology, 9(3), pp.143.

PMCID: PMC5719508

9. Needhidasan S, Samuel, $\mathrm{M} \& \mathrm{R}$ Chidambaram, R. (2014). 'Electronic waste: an emerging threat to the environment of urban India', J. Env. H. Sci. Eng, 12: 36. https://doi.org/10.1186/2052-336X-12-36

10. Pal S, Juyal, D, Adekhandi, S, Sharma, M, Prakash, R, Sharma, N \& Parihar, A. (2015). 'Mobile phones: Reservoirs for the transmission of nosocomial pathogens. Advanced biomedical research', 4, pp. 144. https://doi.org/10.4103/2277-9175.161553

11. Patrick Boshell, (2013) 'Your Mobile Phone Is Dirtier Than You Think' debgroup, 17 July, 2013.

www.debgroup.com/blog/bid/290652/yourmobile-phone-is-dirtier-than-you-think/

12. Rahman MA, Uddin ME, and Ahmed R. (2019). Isolation, identification and antibiotic sensitivity pattern of Salmonella spp. from locally isolated egg samples, Am. J. Pure Appl. Sci., 1(1), 1-11. https://doi.org/10.34104/ajpab.019.019111 
13. S. O'Dea. (2020). "Number of smartphone users worldwide from 2016 to 2021" Statista 12 Mar, 2020.

www.statista.com/statistics/330695/numberof-smartphone-users worldwide/

14. Sani Marc (2017). "Shocking Statistics on Cell Phones and Germs" Sani Marc Group, 7 November, 2017.

www.sanimag.sanimarc.com/shockingstatistics-on-cell-phones-and-germs/

15. Shahaby AF, Awad, NS, El-Tarras, AE \& Bahobial, AS. (2012). 'Mobile phone as potential reservoirs of bacterial pathogens', African Journal of Biotechnology, 11(92), 15896-15904.

https://doi.org/10.5897/AJB12.1836

16. Cerda B, Soto C, Albaladejo MD, Martinez P, Sanchez-Gascon F, Tomas Barberan F \&
Espin JC. (2006). 'Pomegranate juice supplementation in chronic obstructive pulmonary disease: a 5-week randomized, double-blind, placebo-controlled trial', Europ J Clin Nutr, 60, 245-253.

https://doi.org/10.1038/sj.ejen.1602309

17. Vivekananda VA. (2017). 'Isolation and identification of common bacterial contaminants in mobile phones owned by veterinary undergraduate students', Journal of Health, Medicine and Nursing, 35, 93105.

18. Yu W, Kim, HK, Rauch, S, Schneewind, O \& Missiakas, D. (2017). 'Pathogenic conversion of coagulase-negative staphylococci', Microbes and infection, 19(2), 101-109.

https://doi.org/10.1016/j.micinf.2016.12.002

Citation: Islam S, Moniruzzaman M, Pramanik MJ, Jabin T, Mostari MM, Biswas J, Al-Imran, Uddin MS, Saleh MA, ShahriarZaman. (2020). Molecular identification and characterization of smartphone screen associated pathogenic bacteria. Am. J. Pure Appl. Sci., 2(3), 94-103.

https://doi.org/10.34104/ajpab.020.0940103 @) $\underset{\mathrm{BY}}{\mathbf{9}}$ 